\title{
Effect of adjusted pH prior to ultrafiltration of skim milk on membrane performance and physical functionality of milk protein concentrate
}

\author{
X. Luo, T. Vasiljevic, and L. Ramchandran ${ }^{1}$ \\ Advanced Food Systems Research Unit, College of Health and Biomedicine, Victoria University, Melbourne, Victoria 8001, Australia
}

\begin{abstract}
Processing conditions during ultrafiltration of skim milk influence properties of the casein micelle and thereby the physical properties of milk protein concentrate (MPC). The aim of the study was to establish the effects of $\mathrm{pH}$ adjustment of skim milk feed to obtain MPC with desired emulsification properties. The ultrafiltration was conducted using commercially pasteurized skim milk with the $\mathrm{pH}$ adjusted to 6.7 (control), $6.3,5.9$, or 5.5 at $15^{\circ} \mathrm{C}$ until a volume concentration factor of 5 was reached. Effects of $\mathrm{pH}$ adjustment on selected physico-chemical properties (Ca content, particle size, $\zeta$-potential) and functionalities (solubility, heat stability, emulsification capacity, and stability) of MPC were determined. Lowering the feed $\mathrm{pH}$ solubilized colloidal calcium phosphate that substantially contributed to modifying the properties of casein. This caused a reduction in the particle size while increasing the net negative charge. The structural modifications in proteins were manifested in the Fourier transform infrared spectra. Subsequent concentration did not induce any further protein structural changes. Such modifications to the casein micelles and colloidal calcium phosphate negatively affected the solubility and heat stability of the corresponding MPC powders. However, the emulsion activity index improved only until the $\mathrm{pH}$ of the feed was lowered to 5.9 and declined when $\mathrm{pH}$ was dropped to 5.5, followed with the loss of stability. Readjusting the $\mathrm{pH}$ of MPC powder dispersions to 6.7 restored their surface properties and thereby their functionality. Lowering the feed $\mathrm{pH}$ also negatively affected the membrane performance by clogging the membrane pores and lowering the flux, particularly at $\mathrm{pH}$ 5.5. Adjusting $\mathrm{pH}$ to 5.9 produced MPC with optimum emulsifying properties with minimal influence on membrane performance.
\end{abstract}

Received May 21, 2015.

Accepted October 19, 2015.

${ }^{1}$ Corresponding author: lata.ramchandran@vu.edu.au
Key words: pH, ultrafiltration, milk protein concentrate, calcium

\section{INTRODUCTION}

Milk protein concentrate (MPC) is a product obtained by membrane processing and drying, containing all the $\mathrm{CN}$ and whey proteins present in skim milk, thereby delivering the value of the same $\mathrm{CN}$ to whey protein ratio as skim milk. This product provides a protein-rich nutritional source of milk solids, allowing textural modifications with enhanced emulsification capacity that has been used in cheese, processed cheese, and yogurt manufacturing and is commercially available in a range of protein levels (Ye, 2011). Physical functionality of MPC is an important characteristic governing applications of these protein concentrates in food products. Fundamental research on the functional properties of proteins and how these properties can be manipulated by processing are thus essential to improve MPC functionality. Emulsifying ability is one of the most important functionalities of MPC (Cameron et al., 1991). In an emulsion, a dispersion of one liquid in another, such as oil in water, a protein acts as a surface active component forming an interface between these 2 immiscible liquids. This reduces the interfacial energy and therefore increases the stability of the emulsion by creating a more thermodynamically stable system (Becher, 2001).

Several studies have shown that functionality of MPC including solubility and emulsification could be related to properties of the CN micelle (Schuck and Demeler, 1999; Schuck et al., 2002; Udabage et al., 2012). Structural changes of the CN micelle are primarily governed by mineral equilibrium in milk and a state of the colloidal calcium phosphate (CCP). Approximately two-thirds of the milk calcium is involved in complexation with phosphate, creating the $\mathrm{CCP}$ and stabilizing the $\mathrm{CN}$ micelle framework at the normal $\mathrm{pH}$ of milk (Walstra, 1990). The remaining portion is commonly termed soluble calcium and found in the serum phase of milk, thus creating equilibrium between the colloidal and soluble phase (Pierre and Brule, 1981). Any envi- 
ronmental change (temperature, $\mathrm{pH}$, ionic strength) in milk would lead to a shift in the CN-mineral equilibrium, resulting in an increase or decrease in concentration of free calcium ions, dissolution of the CCP from the micelle and release of specific $\mathrm{CN}$ from the micelle (Griffin et al., 1988; Holt, 1992; Gaucheron, 2005), and consequently causing the change of the micelle size. Reduction of the particle size, calcium content, or both appears to be a plausible strategy in producing MPC with good emulsifying properties (Ye, 2011).

Evidently a simple UF followed by a diafiltration of skim milk, although efficient in removing soluble calcium, produced MPC with a poor solubility (Udabage et al., 2012) or emulsification (Ye, 2011). Modifications of the CN micelle appear a necessary step to achieve desired functionalities, and these can be brought about by several approaches that would modify properties and state of the CCP including temperature (Luo et al., 2015), pH (Dalgleish and Law, 1989; Silva et al., 2013), or different chelators (Kaliappan and Lucey, 2011). Due to a multitude of effects, it is of a great importance to establish optimum processing conditions leading to MPC with required functionalities. Ultrafiltration temperature, for example, not only affected the CN micelle size but also the membrane performance with higher temperatures $\left(50^{\circ} \mathrm{C}\right)$, resulting in a smaller particle size but an impaired flux and enhanced fouling than lower temperatures of 15 or $30^{\circ} \mathrm{C}$ (Luo et al., 2015). Due to a profound effect of $\mathrm{pH}$ on the properties of the CN micelle (Matia-Merino and Singh, 2007), it would be necessary to establish an optimum $\mathrm{pH}$ during UF processing that would result in efficient production of functional MPC. The CCP begins to dissociate when $\mathrm{pH}$ is decreased from that of normal milk (Van Hooydonk et al., 1986). Its dissociation can induce dissociation of individual CN (Holt et al., 1986) that can affect the structural integrity of $\mathrm{CN}$ micelle, which in turn may affect their functionality. The $\mathrm{pH}$ range between 5.5 and 6.7 appears critical for inducing fundamental changes in the $\mathrm{CN}$ micelle due to $\mathrm{Ca}^{2+}$ complexation with CN (Rabiller-Baudry et al., 2009).

Along with changes to $\mathrm{CCP}$, structural changes to proteins are also likely to occur that may further bear relation to modifications in their functionality. Of the various techniques used to study protein conformation, Fourier transform infrared (FTIR) spectroscopy provides valuable information about protein folding, denaturation, protein-protein interaction, and subunit assembly, which in turn can aid to the understanding of protein functionality. The location of both amide I and II bands are sensitive to the secondary structural content of proteins (Carbonaro and Nucara, 2010). High sensitivity to small variations in molecular geom- etry and H-bonding patterns make the amide I band especially useful for the analysis of secondary structural composition and structural changes in proteins (Kong and $\mathrm{Yu}, 2007)$. Characteristic secondary structural features such as $\beta$-sheet, $\beta$-turns, $\alpha$-helix, and random coils can be identified by the characteristic peaks appearing at specific wavelengths. Furthermore, protein aggregation occurring as a consequence of intermolecular $\beta$-sheet formation with the involvement of hydrogen bonds results in the appearance of new bands (Lefevre and Subirade, 2001; Remondetto and Subirade, 2003; Eissa et al., 2006). Very few researchers have attempted to use FTIR to study proteins in MPC (Kher et al., 2007; Haque et al., 2010).

Overall, information on how modifications to feed conditions would influence the functionality of MPC, as well as processing performance of UF membranes is absent, although several predictions could be postulated as outlined above. Therefore, the aim of this study was to establish the effect of CCP solubilization by prior milk acidification on functionality of MPC and membrane performance. For this purpose, skim milk was acidified to $\mathrm{pH} 6.3,5.9$, or 5.5 , ultrafiltered at constant temperature without diafiltration, and resulting powders assessed for selected functionalities.

\section{MATERIALS AND METHODS}

\section{Sample Preparation}

Skim milk, produced by a standard pasteurization process $\left(72^{\circ} \mathrm{C}\right.$ for $\left.15 \mathrm{~s}\right)$ was obtained from a local supplier (Woolworths, Bella Vista, NSW, Australia). To prevent bacterial and fungal growth in the feed during the entire time required for the UF process $(3-4 \mathrm{~h})$, thimerosal (Sigma-Aldrich Pty Ltd., Castle Hill, NSW, Australia), a Hg-based preservative, was added at a concentration of $0.3 \mathrm{~g} / \mathrm{L}$.

As required by the experimental protocol, the samples were adjusted to $\mathrm{pH} 6.3,5.9$, or 5.5 at $15^{\circ} \mathrm{C}$ by the addition of an appropriate volume of $1 \mathrm{M} \mathrm{HCl}$ with constant stirring until a constant $\mathrm{pH}$ was established. The temperature of $15^{\circ} \mathrm{C}$ was selected based on our previous observations of appropriate membrane performance with improved emulsifying properties of the MPC produced (Luo et al., 2015). The $\mathrm{pH}$ of the control (6.7) and the other samples was finally adjusted as required by either $1 M \mathrm{HCl}$ or $1 M \mathrm{NaOH}$. The total volume of all samples was kept constant by addition of an appropriate volume of Milli-Q water to prevent any dilution caused by adding different volumes of $\mathrm{HCl}$ (Silva et al., 2013). 


\section{Preparation of MPC by Ultrafiltration}

All skim milk samples (feed) during UF were maintained at a constant temperature of $15^{\circ} \mathrm{C}$ using a water tank. Similar to our previous study (Luo et al., 2015), a SEPA CF membrane cell module (Sterlitech Corporation, Kent, WA) and a polyethersulfone membrane with a size of $190 \times 140 \mathrm{~mm}$ and molecular mass cut-off of $20 \mathrm{kDa}$ were used in all trials. The samples were pumped (T-VERTER, Hydrocell pump, Wanner Engineering Inc., Minneapolis, MN) through the membrane module at a pressure of 2 bars and frequency of $12.5 \mathrm{~Hz}$ during UF. The processing was stopped when volume concentration ratio (VCF) of 5 was achieved as inferred by measuring the volume of collected permeate. The retentate and permeate samples were collected when required and appropriately processed before frozen storage. For each experimental run, a new membrane sheet was used, which was wetted with Milli-Q water overnight before use. Before each UF run, the membrane module was flushed with Milli-Q water $\left(15^{\circ} \mathrm{C}\right)$ for $10 \mathrm{~min}$. The bulk of retentates at the end of UF runs was immediately frozen and freeze-dried in a freeze dryer (model FD300, Dynavac Eng. Pty. Ltd., Melbourne, Australia). Obtained powders were transferred into plastic containers and stored in a cool, dry room until required for analysis of functionality.

\section{Particle Size and Zeta Potential}

Particle size and zeta potential of the feeds, retentates, and permeate samples were measured immediately after the collection of samples using a Malvern Zetasizer (model ZEN3600, Nano-ZS, Malvern Instruments Ltd., Malvern, UK) as previously described (Luo et al., 2015). The samples were diluted with Milli-Q water as required (1:100 for feed samples and 1:1,000 for MPC samples) to meet quality data requirement during measurement of particle size (Mellema et al., 2009). Thereafter, the samples were gently vortexed (10-15 s) and immediately introduced into the instrument. The measurements were carried out at room temperature $\left(22^{\circ} \mathrm{C}\right)$.

\section{Determination of Ca Content}

The determination of the total $\mathrm{Ca}$ in feed and retentate samples followed the protocol described by StGalais et al. (1992). The samples were first ashed at $550^{\circ} \mathrm{C}$ overnight and then the ash was solubilized in 0.1 $M \mathrm{HCl}$. The soluble Ca was obtained by centrifugation of the feed and retentates at $33,000 \times g$ for $60 \mathrm{~min}$ at $25^{\circ} \mathrm{C}$ (Williams et al., 2008) using Beckman LK $90 \mathrm{M}$ ultracentrifuge with a Type 55.2 Ti rotor [Beckman
Instruments Australia (Pty) Ltd., Gladesville, NSW, Australia]. The obtained supernatant was ashed as described above. The Ca content in all samples was determined using an atomic absorption spectrophotometer (model AA-6300, Shimadzu Corporation, Kyoto, Japan) at $422.7 \mathrm{~nm}$. The Ca concentration was inferred from a standard curve (1 to $10 \mathrm{ppm} \mathrm{Ca}$ ).

\section{ATR-FTIR}

Changes in protein conformation were observed using an FTIR spectrofluorometer (Shimadzu IRAffinity-1, Shimadzu Corporation, Kyoto, Japan) equipped with IRsolution FTIR software (Shimadzu) as described previously (Luo et al., 2015). The samples were analyzed immediately after sampling and spectra were obtained in the absorbance mode using Vee-Max flat plate ZnSe ATR crystal (45 degrees; PIKE Technologies Inc., Fitchburg, WI). For each spectrum, an average of 80 scans was resolved at $4 \mathrm{~cm}^{-1}$ in the range of 400 to $4,000 \mathrm{~cm}^{-1}$ after atmospheric background subtraction. The interferograms thus obtained were ATR corrected, baseline adjusted to zero, smoothed (10 points), and deconvoluted with the aid of the software to recognize the corresponding peaks under the broad amide I region of 1,600 to $1,700 \mathrm{~cm}^{-1}$.

\section{Functionality of MPC}

Physical functionality of MPC produced by the described protocol above was established within $2 \mathrm{wk}$ after preparation. The powders were dispersed in Milli$\mathrm{Q}$ water preheated to $50^{\circ} \mathrm{C}$. These dispersions were further divided into 2 equal portions: the first, which was further assessed without prior $\mathrm{pH}$ adjustment, and the second, in which $\mathrm{pH}$ was readjusted to $\mathrm{pH} 6.7$ using $1 \mathrm{M} \mathrm{NaOH}$. Both portions were subsequently stored at $4^{\circ} \mathrm{C}$ overnight with the constant stirring to allow for full hydration of the powders for analysis. The following day $\mathrm{pH}$ of all dispersions was confirmed and adjusted if required, followed by final concentration adjustments resulting in 5\% (wt/wt) MPC dispersions. The powders contained between 52 and $55 \%$ protein on a dry base.

The protein solubility was estimated using the method originally proposed by Morr et al. (1985) and modified as suggested by Dissanayake et al. (2012). In brief, after overnight storage exactly $10 \mathrm{~mL}$ of protein dispersions was centrifuged (model J2HS, Beckman, Fullerton, CA) at $12,000 \times g$ for $25 \mathrm{~min}$ at $20^{\circ} \mathrm{C}$. The supernatant was filtered through a $0.45-\mu \mathrm{m}$ filter and its protein content was assessed by the Kjeldahl method. The solubility of the powders was expressed as a percentage of the protein remaining in the solution after centrifugation (Luo et al., 2015). 
Heat stability of MPC dispersions was assessed using the solubility method upon heating at $140^{\circ} \mathrm{C}$ for a defined time (Dissanayake et al., 2012) as reported previously (Luo et al., 2015). After reaching the required time, the samples were quickly removed from the oil and submerged into an ice-water bath. The stability of heated dispersions was assessed by measuring the protein content of the supernatant upon centrifugation as described above.

The emulsions were prepared as reported previously (Luo et al., 2015) by mixing one part of canola oil with 3 parts of protein dispersions. After producing fine emulsions by a 2-step homogenization process, the samples were immediately cooled to $25^{\circ} \mathrm{C}$. Emulsification activity index was determined by measuring turbidity of emulsions following the established procedure (Pearce and Kinsella, 1978) and modifications previously reported (Dissanayake et al., 2012; Luo et al., 2015). The emulsion stability index (ESI) was determined after storage at $4^{\circ} \mathrm{C}$ for $24 \mathrm{~h}$ (Dissanayake et al., 2012; Luo et al., 2015).

\section{Membrane Performance}

Membrane performance was evaluated by measuring the permeate flux, followed by an examination of membrane surface and cross section using scanning electron microscopy after completion of UF as reported previously (Luo et al., 2015). The flux was measured every $30 \mathrm{~min}$ by continuously recording the weight of permeate, which also allowed for determination of weight reduction of the feed. The used membranes were rinsed with water, dried at room temperature, and stored at $-20^{\circ} \mathrm{C}$ before the scanning electron microscopy examination. The scanning electron microscopy examination was carried out using a JCM 5000 bench top NeoScopy scanning electron microscope (Swanzey Internet Group, Manchester, UK). The scanning electron microscope was set at Vac-high PC-STD $15 \mathrm{KV}$ during the sample imaging. To prepare samples for cross-section examination, the membrane was first wetted in Milli-Q water and then cut in liquid nitrogen. The membrane samples were mounted on double-sided carbon tape, dried at room temperature overnight, and coated with gold before examination.

\section{Statistical Analysis}

The experiments were designed as a randomized block design with $\mathrm{pH}$ as the main factor (4 levels) and replications as a block. The whole design was replicated 3 times with subsequent subsampling giving at least 6 independent observations $(\mathrm{n} \geq 6)$. One-way ANOVA was conducted to explore the influence of $\mathrm{pH}$ on the functionality of MPC as the main effect, followed by Tukey honestly significant difference post hoc test to determine significant differences between the means at $P<0.05$.

\section{RESULTS AND DISCUSSION}

\section{Physicochemical Properties of Retentates}

The $\mathrm{Ca}$ and phosphate distribution between serum and micellar (CN-bound) phases has great influence on the functional properties of dairy products. The CCP associated with CN micelles can be varied by various treatments such as heating and cooling (Holt, 1995; Luo et al., 2015), the addition of Ca-chelating agents (Udabage et al., 2000), or acidification (Lucey et al., 1996). Similar trend was obtained in the current study with Table 1 showing the total and calcium in the feed and retentates before and after UF, respectively. Indicatively, $\mathrm{pH}$ adjustment resulted in substantial solubilization of the CCP in the original feed. As expected, approximately one-third of the total $\mathrm{Ca}$ was soluble (Lewis, 2011) in the feed at native $\mathrm{pH}$ (control). The soluble portion increased to almost two-thirds of the total Ca with concomitant lowering of $\mathrm{pH}$ (Table 1). Whereas the total operating volume was reduced by 5 times, total Ca concentration increased by approximately 3.5 times, indicating that colloidal phase was concentrated. Even upon concentration, a fraction of $\mathrm{Ca}$ was in the soluble form, which may indicate reestablishment of the mineral equilibrium. At neutral $\mathrm{pH}$, the soluble portion of the total $\mathrm{Ca}$ in the retentate was $15.5 \%$. As the $\mathrm{pH}$ declined, this proportion increased from $17.9 \%$ at $\mathrm{pH} 6.3$, to 20.9 at $\mathrm{pH} 5.9$, and finally to 29.1\% at pH 5.5. Li and Corredig (2014) have reported similar values at $\mathrm{pH} 5.5$.

As the CCP was solubilized during acidification, the CN micelle structure did not appear to be substantially affected, which was reflected in the particle size distribution (Figure 1). The particle size distribution of the CN micelles shifted initially toward smaller sizes when $\mathrm{pH}$ of the feed was changed from 6.7 to 5.9 (Figure 1). No further change was observed when $\mathrm{pH}$ was adjusted to 5.5, being similar to particle size distribution at $\mathrm{pH} 5.9$. At natural $\mathrm{pH}$ of skim milk, individual $\mathrm{CN}$ are associated in the form of micelles, the diameter of which varies depending on ionic conditions, but in general about $200 \mathrm{~nm}$ in diameter. The origin of stability of the micelles has been partly attributed to phosphocalcic bridge between phosphorylated lateral chains of CN structure and Ca (Law and Leaver, 1998). Upon acidification, proton addition causes association of $\mathrm{H}^{+}$with citrate, inorganic, and organic phosphates, inducing increase of ionic $\mathrm{Ca}$ concentration, and de- 
crease in micellar hydration and zeta potential, leading to solubilization of micellar calcium phosphate (Law and Leaver, 1998). This also results in decline in CN micelle voluminosity (Vreeman et al., 1989) and its particle size (Silva et al., 2013). Another contributing factor to change in particle size could be dissolution of $\mathrm{CN}$ from the micelle, which has been found to be higher at lower $\mathrm{pH}$ values of $\sim 5.5$ even at $20^{\circ} \mathrm{C}$ (Dalgleish and Law, 1988). It is not clear if UF process had an effect on the decrease of the particle size, although this was reported previously (Srilaorkul et al., 1991). Studies examining mineral equilibrium and effect on the CN micelle integrity in milk have been conducted in thermodynamically closed systems (a closed membrane processing loop), in which total mineral content remained constant. In our study, however, continuous removal of $\mathrm{Ca}$ by its permeation through the membrane would likely shift equilibrium between CCP and soluble $\mathrm{Ca}$ and thus induce further changes of the $\mathrm{CN}$ micelle, potentially leading to a reduction of micelle particle size. Furthermore, in the $\mathrm{pH}$ range between 5.2 and 5.9, the CN micelle undergoes many physico-chemical changes (Vreeman et al., 1989; Walstra, 1990), which, accompanied with a shift in the Ca equilibrium due to UF, would likely result in MPC with a smaller particle size (Srilaorkul et al., 1991).

Removal of minerals, in particular Ca, by UF affected zeta potential (Figure 2). As the feed was acidified and $\mathrm{pH}$ declined from 6.7 to 5.5 , the net negative charge decreased from -32.8 to $-27.6 \mathrm{mV}$. On the other hand, zeta potential of the corresponding retentates at the end of UF increased from -33.7 to $-37.9 \mathrm{mV}$. This type of observation was expected because negatively charged sites of $\kappa-\mathrm{CN}$ would become neutralized by proton addition and solubilization of the CCP (Walstra, 1990). The exterior of the micelles mainly consists of hydrophilic negatively charged $\kappa-\mathrm{CN}$, which provides both electrostatic and steric stabilization to the CN micelle. The negative charge is caused by dissociated carboxyl and ester phosphate group. When $\mathrm{pH}$ decreases, the CN-mineral equilibrium is shifted increasing the repulsion between the negatively charged $\mathrm{AA}$ in the $\mathrm{CN}$

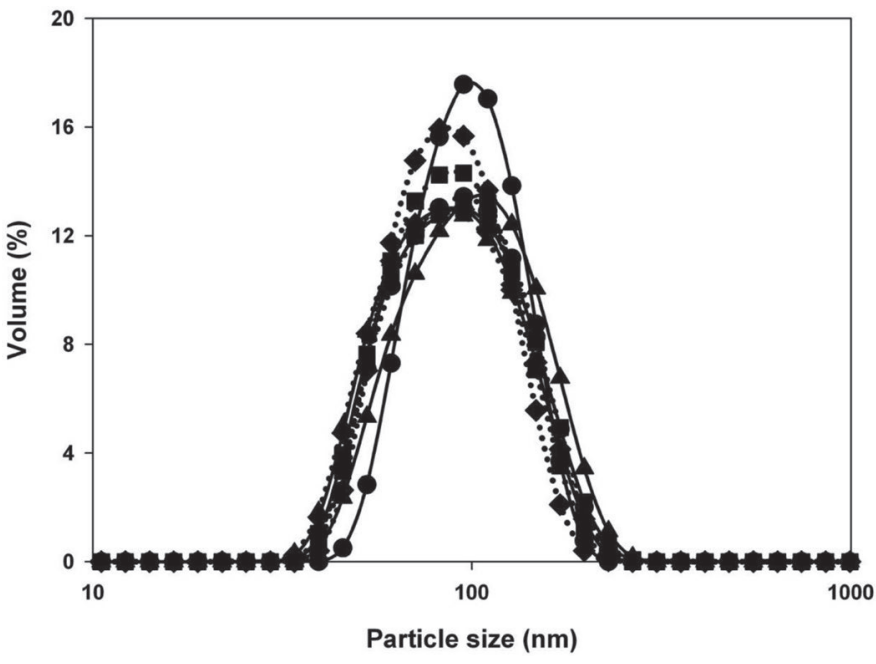

Figure 1. Particle size distribution of feed (solid line) and retentate (dotted line) at volume concentration factor of 5 obtained by UF of skim milk with adjusted $\mathrm{pH}$ at $6.7(\bullet), 6.3(\mathbf{\Delta}), 5.9(\mathbf{\square})$, or $5.5(\diamond)$ at $15^{\circ} \mathrm{C}$.

micelles, leading to a decrease in concentration of free $\mathrm{Ca}$ ions, dissolution of $\mathrm{CCP}$ from micelle, and release of specific CN from the micelle (Liu and Guo, 2008). Contribution of soluble $\mathrm{Ca}$ to charge screening at low $\mathrm{pH}$ appeared substantial as preferential removal of $\mathrm{Ca}$ from the micelle by CPP dissolution and by UF from the feed (Vasiljevic and Jelen, 1999) augmented negative surface potential of the particles (Figure 2) along with the neutralization effect of positively charged groups caused by lowering of $\mathrm{pH}$. This could potentially contribute to the decrease in particle size due to greater electrostatic repulsion along with concomitant collapse of the $\kappa$-CN hairy layer (Walstra, 1990) as well as due to solubilization of CCP.

\section{Structural Changes in Milk Proteins}

Fourier transform infrared interferograms of the feed (Figure 3A) showed typical peaks associated with the secondary structure of proteins such as $\beta$-sheets $(1,631-$

Table 1. Total and soluble Ca (mean $\pm \mathrm{SD})$ in feed and retentates after $5 \times$ volume concentration during UF of skim milk at $15^{\circ} \mathrm{C}$ with $\mathrm{pH}$ adjusted to $6.3,5.9$, or 5.5

\begin{tabular}{|c|c|c|c|c|}
\hline \multirow[b]{2}{*}{$\mathrm{pH}$} & \multicolumn{2}{|c|}{ Total Ca $(\mathrm{m} M)$} & \multicolumn{2}{|c|}{ Soluble Ca $(\mathrm{m} M)$} \\
\hline & Feed & $\begin{array}{c}\text { Retentate, } \\
\mathrm{VCF}^{1} 5\end{array}$ & Feed & $\begin{array}{c}\text { Retentate, } \\
\text { VCF } 5\end{array}$ \\
\hline Control & $31.1 \pm 0.8$ & $103.6 \pm 0.2$ & $12.4 \pm 0.8$ & $16.1 \pm 0.3$ \\
\hline 6.3 & $32.2 \pm 0.4$ & $98.9 \pm 1.2$ & $15.3 \pm 0.6$ & $17.7 \pm 0.4$ \\
\hline 5.9 & $31.4 \pm 0.7$ & $95.4 \pm 0.7$ & $17.9 \pm 1.2$ & $20.0 \pm 0.2$ \\
\hline 5.5 & $32.7 \pm 0.8$ & $85.0 \pm 0.4$ & $25.2 \pm 1.2$ & $24.8 \pm 0.1$ \\
\hline
\end{tabular}

${ }^{1} \mathrm{VCF}=$ volume concentration ratio. 


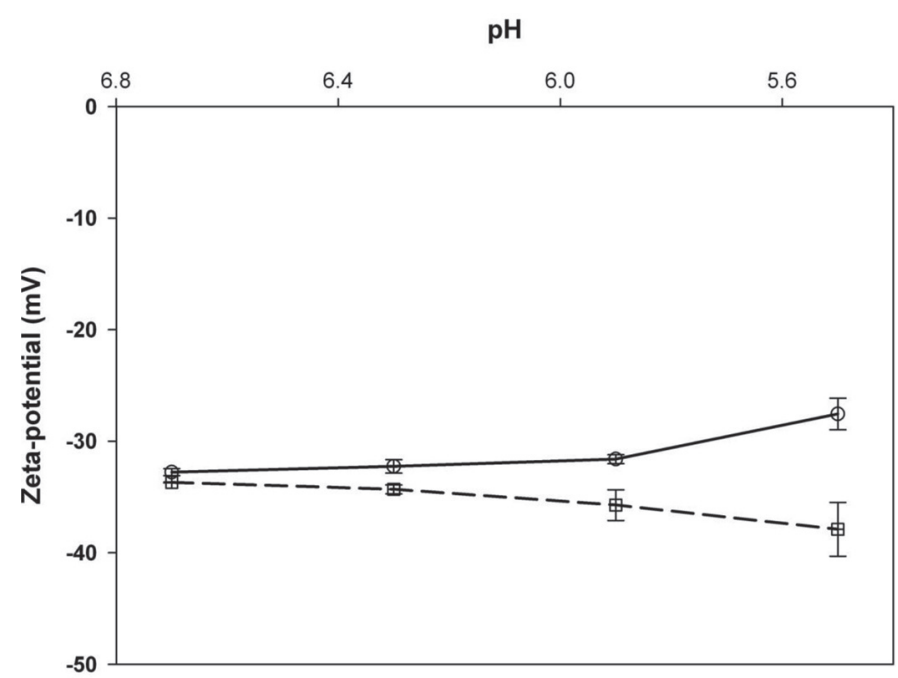

Figure 2. Zeta-potential obtained at the beginning $(-\mathrm{O}-)$ ) and the end (-- $\square--)$ of UF of skim milk at adjusted pH and constant processing temperature of $15^{\circ} \mathrm{C}$. Error bars represent SD.

1,635 $\left.\mathrm{cm}^{-1}\right)$, random coils $\left(1,640-1,650 \mathrm{~cm}^{-1}\right)$, and $\alpha$-helix $\left(1,650,1,657\right.$, or $\left.1,658 \mathrm{~cm}^{-1}\right)$. Changing the $\mathrm{pH}$ of the feed before UF showed a shift in position along with increasing intensity of peak representing $\beta$-sheets. The peak appearing at $1,627 \mathrm{~cm}^{-1}$ in the control shifted to 1,629 at $\mathrm{pH} 6.3,1,632$ at $\mathrm{pH} 5.9$, and finally to 1,634 at $\mathrm{pH} 5.5$, suggesting the formation of disordered structures and intermolecular $\beta$-sheet associated aggregation as the $\mathrm{pH}$ of the feed was lowered. Similar changes were also exhibited by the peak representing random coil structure at $1,643 \mathrm{~cm}^{-1}$. Moreover, appearance of well-defined peaks at 1,681 and 1,693 $\mathrm{cm}^{-1}$, related to antiparallel intermolecular $\beta$-sheet aggregation and denatured compounds, respectively, indicated that lowering the $\mathrm{pH}$ of feed to 5.9 or 5.5 caused substantial denaturation and aggregation of proteins. The fact that whey proteins tend to form aggregates with $\mathrm{CN}$ at $\mathrm{pH}$ closer to their isoelectric point $(\mathrm{pH} \sim 5.2$; Nair et al., 2013) explains the appearance of such peaks $\left(1,681\right.$ and $\left.1,693 \mathrm{~cm}^{-1}\right)$ at $\mathrm{pH} 5.9$ and 5.5 as well as the shift observed in peak representing $\beta$-sheets. Further, solubilization of CCP with decreasing $\mathrm{pH}$ in the feed could lead to dissociation of CN (McMahon and Oommen, 2013), which could further explain the increased possibility of protein interaction leading to formation of aggregates. This supports our earlier observation of increase in soluble $\mathrm{Ca}$ (to $>20 \%$ of total Ca) when $\mathrm{pH}$ was lowered to 5.9 and 5.5, strengthening the possibility of CN dissociation due to solubilization of CCP.

Concentrating the skim milk at any defined $\mathrm{pH}$ did not cause any major structural changes as was observed by the persistence of similar peaks in the corresponding retentates (Figure 3B). The peak intensities of some typical peaks increased such as those appearing at $1,631 \mathrm{~cm}^{-1}$ (control, $\mathrm{pH} 6.3$ and 5.9), as well as the peak at $1,634 \mathrm{~cm}^{-1}$ and those representing denatured components at $\mathrm{pH} 5.5$, which could be a consequence of the concentration effect of UF. However, the appearance of well-defined peaks at 1,658 (control and $\mathrm{pH}$ 5.9 and 5.5) and $1,663 \mathrm{~cm}^{-1}(\mathrm{pH} 6.3)$, indicative of $\alpha-$ and $3_{10}$ helical structures, respectively, suggest further randomness in the structural integrity of proteins as a consequence of UF or increased solubilization of CN as the $\mathrm{pH}$ was lowered.

\section{Functional Properties of MPC}

Milk proteins, due to their amphiphilic nature, play an important functional role in food. Among various
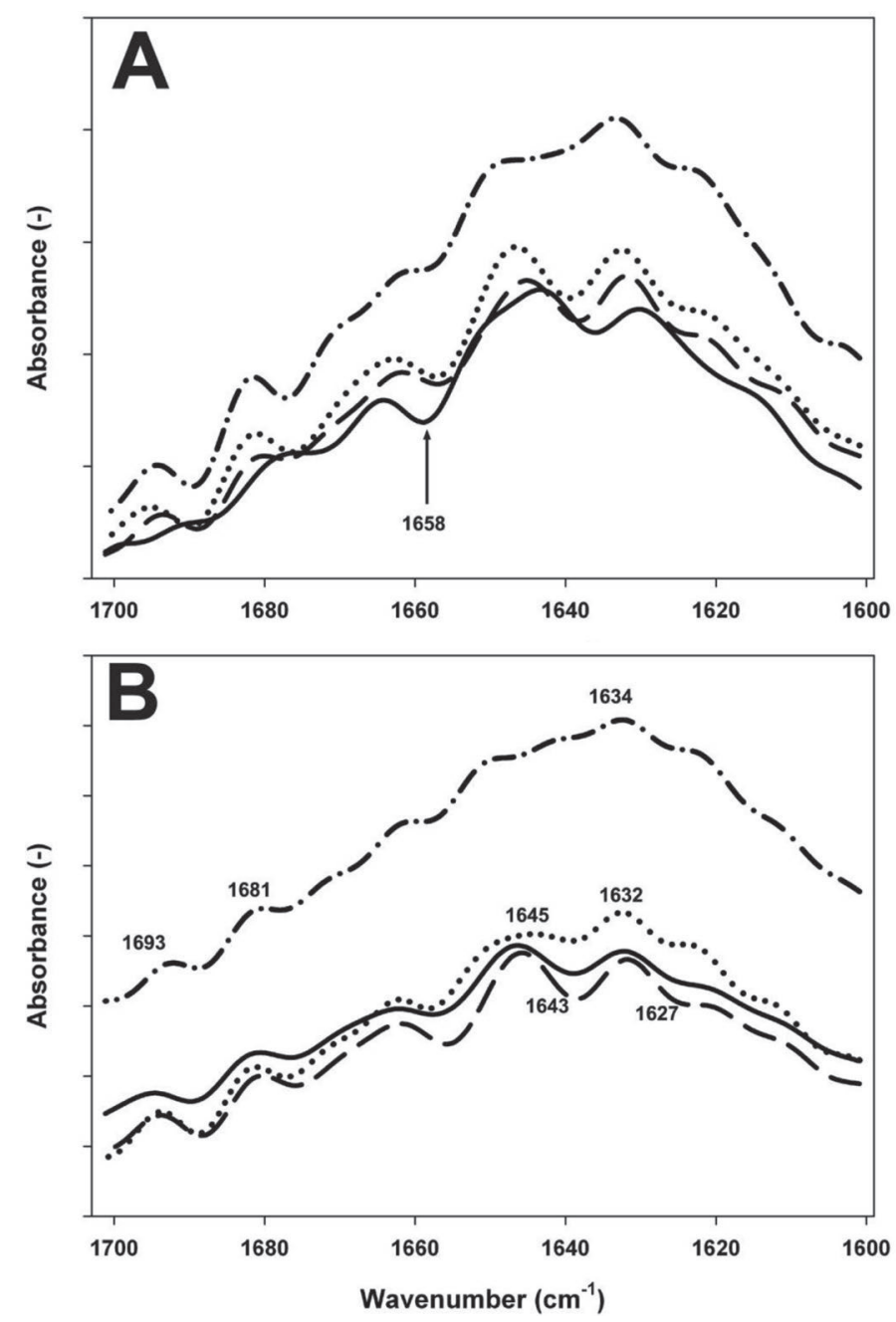

Figure 3. Fourier transform infrared interferograms depicting structural changes of proteins upon $\mathrm{pH}$ in feed (A) and the corresponding retentates (B) after UF at $15^{\circ} \mathrm{C}$ and volume concentration factor of 5. Pasteurized skim milk samples had $\mathrm{pH}$ adjusted to 6.3 (- -), $5.9(\cdots)$, and $5.5(-\cdot)$ and included control $(-)$ with $\mathrm{pH}$ of 6.76 . 
functional properties, solubility is of primary importance due to its effect on the other functionalities (Halling, 1981). Numerous studies pointed out that changes in operating conditions during membrane processing affect the composition and functionality of the MPC powders produced (Udabage et al., 2012). One of the limiting factors in widespread use of MPC powders is its poor solubility, which is further compromised during storage, mainly attributed to association of $\mathrm{CN}$ molecules by hydrophobic interactions (Havea, 2006) and migration of residual fat to the surface of the powder particle (Gaiani et al., 2009). Pasteurization of milk before MPC production has also been shown to induce a certain degree of protein aggregation mainly via disulfide bonds (Havea, 2006) that could consequently influence MPC solubility. Earlier, McKenna (2000) observed that large particle formed in MPC negatively affected its solubility. These particles consisted of $\mathrm{CN}$ micelles that somehow interacted and fused together. Figure 4 shows the comparison of solubility and heat stability of the reconstituted MPC powders obtained by freeze drying of retentates concentrated from the skim milk adjusted to different $\mathrm{pH}$. Solubility and heat stability of reconstituted powders (Figure 4) was established at adjusted and neutralized $\mathrm{pH}$ (6.7).

The solubility of MPC dispersions declined substantially $(P<0.05)$ from $\sim 77$ to $32 \%$ as $\mathrm{pH}$ of the feed was adjusted from 6.7 (control) to 5.5, respectively. However, this trend was reversed when $\mathrm{pH}$ of dispersions was neutralized back to 6.7. Solubility of MPC dispersions obtained at $\mathrm{pH} 5.9$ and 5.5 was even greater $(P<$ $0.05)$ than that of the control $(87.9 \pm 1.0$ and $89.7 \pm$ 0.7 , respectively). The heat stability followed a similar trend, declining from $\sim 96 \%$ to $\sim 8 \%$ at $\mathrm{pH} 6.7$ and 5.5, respectively, as $\mathrm{pH}$ was lowered before UF. Neutralizing $\mathrm{pH}$ of the dispersions once again improved heat stability, which was comparable among the samples ranging between $\sim 72$ and $78 \%$ at $\mathrm{pH} 5.5$ and 6.7 , respectively (Figure 4). Among various factors influencing protein solubility, $\mathrm{pH}$ plays a central and important role. At $\mathrm{pH}$ above and below their $\mathrm{pI}$, proteins have a net negative or positive charge, respectively, which contributes

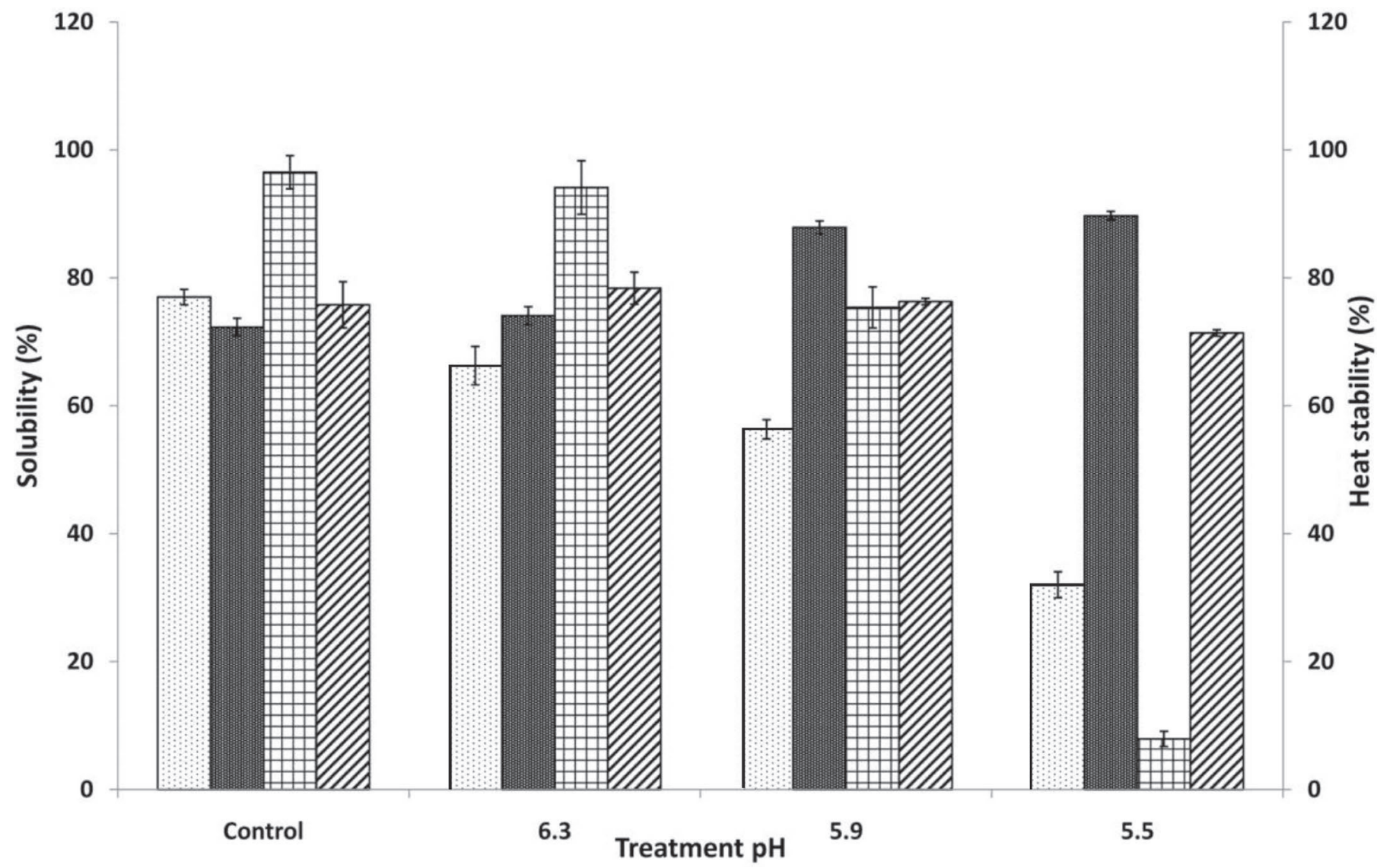

Figure 4. Solubility, before (dotted) and after (dark gray) pH adjustment, and heat stability, before (cross-hatch) and after (diagonal lines) $\mathrm{pH}$ adjustment, of $5 \%$ (wt/wt) dispersions prepared from milk protein concentrate powders obtained by $\mathrm{UF}$ of $\mathrm{pH}$ adjusted skim milk at $15^{\circ} \mathrm{C}$. Error bars represent SD. 
to overall protein stability and consequently solubility. At $\mathrm{pH}$ closer to isoelectric point, $\mathrm{CN}$ micelle starts to change due to collapse of $\kappa$-CN hairy layer and solubilization of the CCP, resulting in compromised steric hindrance and lower electrostatic repulsions due to released $\mathrm{Ca}^{2+}$ (Table 1, Walstra, 1990). This, accompanied with a lower processing temperature, can result in dissolution of CN (Dalgleish and Law, 1988), leading to a system with substantially different physical properties upon drying and redispersion. Modified surface properties likely resulted in poor dispersability and enhanced aggregation, which was manifested by poor solubility. Additionally, released $\beta$-CN might have been located on the surface of particles upon water removal, which further enhanced hydrophobic interactions upon reintroduction into solution driving particles toward aggregation and poor solubilization. These interactions, however, appeared minimized upon neutralization, which have likely recovered some of the initial surface properties.

Differences in the heat stability of milk have been attributed to variations in the composition of milk salts and presence or absence of the CCP (O'Connell and Fox, 2003). For example, Ghatak et al. (1989) reported that the heat stability of both bovine and buffalo milk is significantly correlated with soluble Ca content, whereas Pouliot and Boulet (1995) correlated the heat stability of concentrated milk with the ratio of colloidal Ca to colloidal phosphate. Furthermore, mode of milk protein concentration has a marked effect on heat stability. Concentrates prepared by UF were more stable than those produced by conventional evaporation, which was attributed to a reduction in the concentration of lactose and soluble Ca (Sweetsur and Muir, 1980). Lowering $\mathrm{pH}$ beyond 6.0 before UF resulted in concentrates with compromised heat stability (Muir and Sweetsur, 1984), once again indicating substantial changes of surface properties invariably leading to low solubility and heat stability. Apparently some of these physicochemical changes may be reversed by $\mathrm{pH}$ readjustment upon redispersion, thus improving solubility and heat stability. Similarly, Ezeh and Lewis (2011) observed improved heat stability of skim milk when the $\mathrm{pH}$ was readjusted to 6.47 from 5.45, which they attributed to restoration of $\mathrm{CCP}$.

Modified particle properties may ultimately lead to improved or compromised interfacial functionality. The emulsion activity index (EAI) and ESI of reconstituted MPC powders obtained by $\mathrm{pH}$ adjustment are presented in Figure 5. Lowering $\mathrm{pH}$ to 5.9 improved $(P<0.05)$ EAI; however, it consequently declined $(P$ $<0.05)$ at $\mathrm{pH} 5.5$. This trend was conversely reversed upon neutralization with EAI at $\mathrm{pH} 5.5$ being similar
$(P>0.05)$ to that at $\mathrm{pH} 5.9$ and greater than EAI at $\mathrm{pH} 6.7$ or 6.3 (Figure 5). The emulsion stability as indicated by ESI on the contrary was greater $(P<0.05)$ at the control $\mathrm{pH}$ and steadily declined $(P<0.05)$ as $\mathrm{pH}$ was lowered in the feed. Interestingly neutralization completely reversed this trend, with the most stable emulsion obtained from MPC obtained at $\mathrm{pH} 5.9$, being almost unchanged during the time of experimentation.

Emulsion activity index is a measure of the capability of a protein to stabilize the interface between 2 immiscible phases, such as oil and water (Dickinson, 1992; Dalgleish, 2006). Stability of an emulsion depends on the balance of several forces including attractive, repulsive, steric, and depletion forces (Dickinson, 1997). The structure of an emulsion can change in several ways including creaming, flocculation, or coalescence, or their combinations (Ferragut and Chiralt, 1996; Dickinson and Golding, 1997). Thus emulsion stabilization may be provided by hindering these processes and the manipulating forces driving them. For an emulsion to remain kinetically stable, repulsive forces need to be greater than attractive forces. From Figure 5, it is obvious that MPC powders had different emulsification properties likely governed by surface properties of constituting particles. Dispersions prepared by MPC without $\mathrm{pH}$ adjustment apparently had compromised solubility that consequently affected redistribution of protein particles on the interface and thus emulsifying capacity. Upon neutralization, many amphiphilic properties were restored and probably improved because MPC obtained at pH 5.9 and 5.5 had greater EAI and ESI than those obtained by UF at 6.7 or 6.3 (Figure 5). Such an improvement could partially be attributed to reduced particle size, although it does not appear as a governing factor at a lower $\mathrm{pH}$ because MPC obtained at 5.5 and 5.9 had similar particle size distributions (Figure 1). Loss of steric hindrance and hydrophilicity by collapsing $\kappa$-CN (O'Connell and Fox, 2003) might have rendered resulting $\mathrm{CN}$ micelles more hydrophobic and prone to associations, and thus poor solubility. This, however, upon $\mathrm{pH}$ neutralization this might have been counteracted by increased electrostatic repulsion due to lack of soluble Ca in solution, and thus improved solubility. However, rather looser structure due to depletion of the CCP at low $\mathrm{pH}$ and likely reorganization of individual CN (Anema and Klostermeyer, 1997; Vasbinder and de Kruif, 2003) resulted in smaller particles with enhanced emulsifying properties. Although it is not evident from the current study, dissolution of CN during UF at low temperature is expected; however, it is difficult to predict its fate during further processing and whether it plays any role in improved emulsification. A recent study has found that $\beta-\mathrm{CN}$ is 


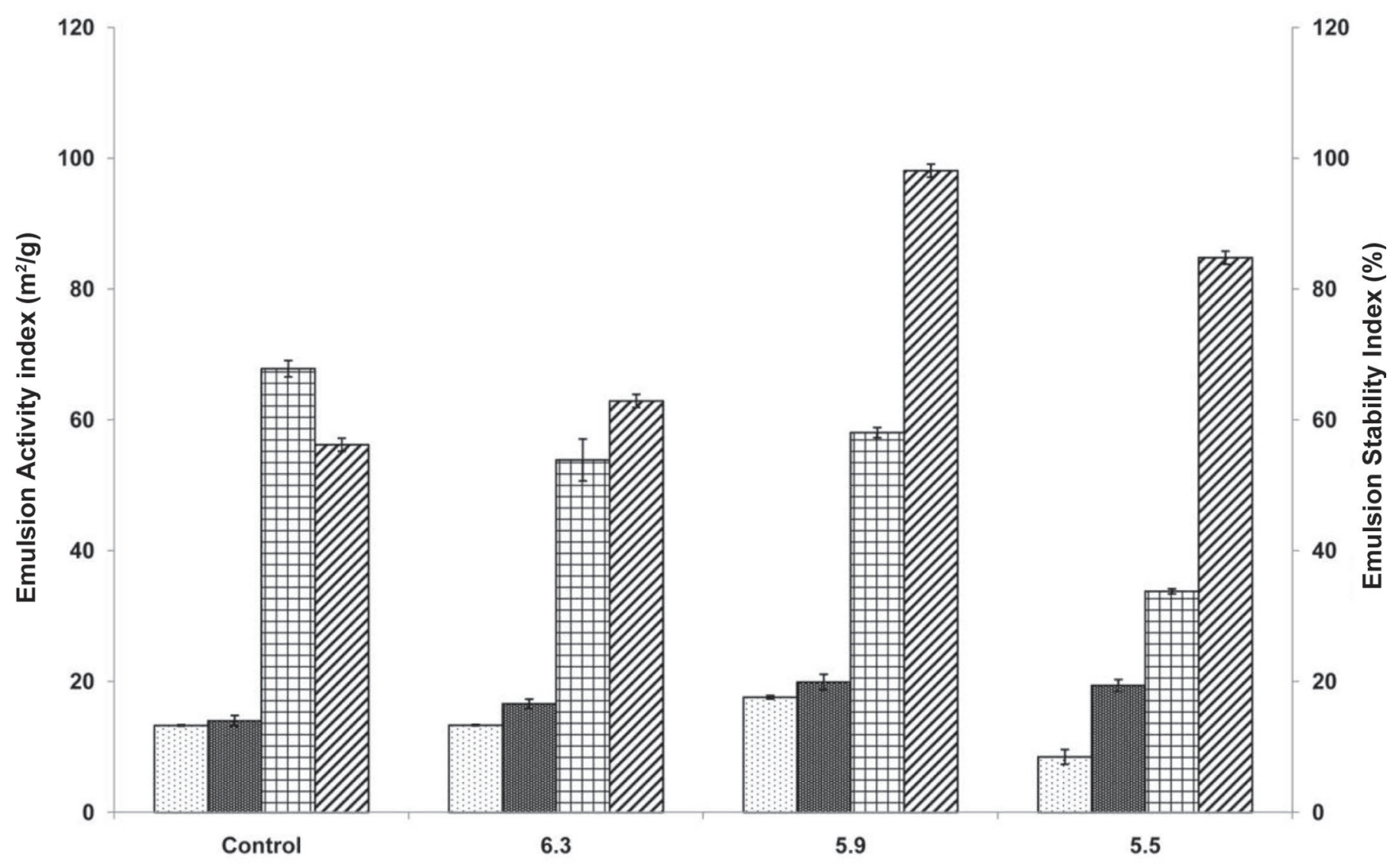

Figure 5. Emulsion activity index, before (dotted) and after (dark gray) pH adjustment, and emulsion stability index, before (cross-hatch) and after (diagonal lines) $\mathrm{pH}$ adjustment, of emulsions prepared from milk protein concentrate powders obtained by UF of $\mathrm{pH}$ adjusted skim milk at $15^{\circ} \mathrm{C}$. Error bars represent SD.

highly hydrophobic and prone to self-associations, creating different micellar forms and modifying behavior of other proteins present (Liyanaarachchi et al., 2015).

\section{Membrane Performance}

Achieving a balance between process parameters to obtain MPC of required functionality and membrane performance is of paramount importance. The membrane performance was initially assessed by flux determination and further elaborated on by the scanning electron microscopy characterization. As expected, the flux declined steadily over time during UF irrespective of adjusted $\mathrm{pH}$ (Figure 6). Indicatively, the flux was similar $(P>0.05)$ for all UF runs at $\mathrm{pH} 5.9$ and above. The flux deteriorated substantially $(P<0.05)$ as $\mathrm{pH}$ was adjusted to 5.5. In principle, it took approximately $3.5 \mathrm{~h}$ to achieve $\mathrm{VCF}$ of 5 , whereas this time was extended at $\mathrm{pH} 5.5$ to $4 \mathrm{~h}$. Apparently, $\mathrm{pH}$ adjustment in the feed before UF induced significant changes in surface properties of the $\mathrm{CN}$ micelle that resulted in enhanced surface activity and subsequent greater fouling at lower $\mathrm{pH}$. This membrane fouling was also observed by scanning electron microscopy (Figure 7). The cross section of the membrane operated at $\mathrm{pH}$ 6.7 appeared clean as indicated by the presence of some clear pores on the surface and rigid supporting wall. As $\mathrm{pH}$ was lowered to 5.5, the extent of membrane fouling became substantial, with pores and supporting wall being almost completely blocked at pH 5.5 (Figure 7). The reduction in size of $\mathrm{CN}$ micelle (Figure 1) as well as change to its surface properties (Figure 2) at $\mathrm{pH}$ 5.5 could have promoted its adherence to membranes leading to extensive fouling. Overall, the slight flux decline appeared to follow the generation of the fouling layer and increased deposition of solids; flux is therefore controlled by diffusion resistance in this layer. However, the extent of fouling observed in Figure 7 was not in line with the observed differences in flux. Although the fouling layer at $\mathrm{pH} 5.5$ appeared thicker, the flux was fractionally lower, especially in the initial stages. This indicated that the flux at this $\mathrm{pH}$ was hindered immediately, whereas further flux declined at a similar rate as that at other $\mathrm{pH}$ levels. 


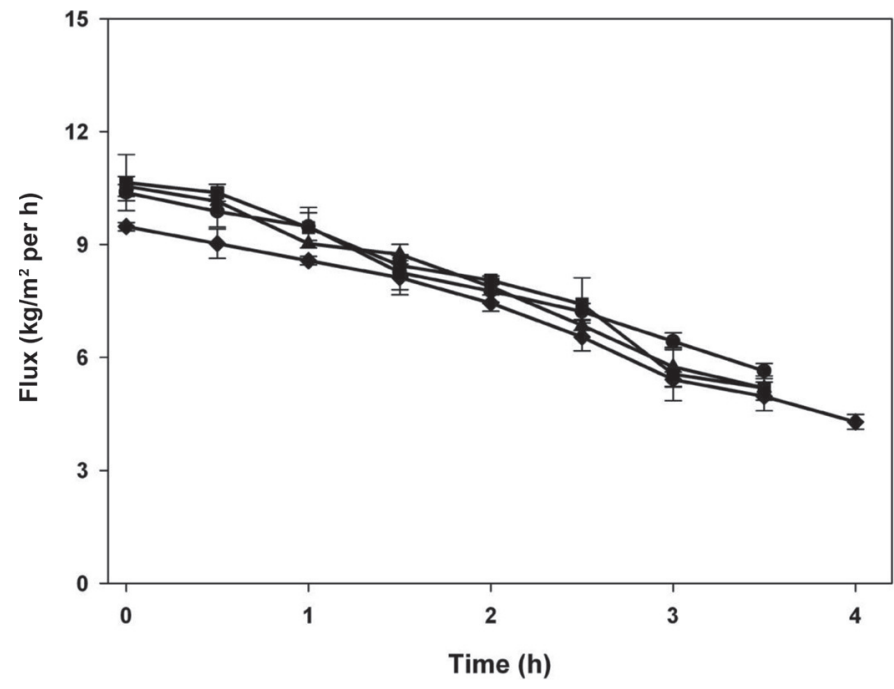

Figure 6. Permeate flux during UF of skim milk with adjusted $\mathrm{pH}$ at $6.7(\bullet), 6.3(\mathbf{\Delta}), 5.9(\mathbf{\square})$, or $5.5(\bullet)$ at $15^{\circ} \mathrm{C}$ to a volume concentration factor of 5 . Error bars represent SD.
Membrane fouling in the dairy industry mainly arises from the composition and properties of the treated fluid apart from the effects of operation parameters (e.g., pressure, temperature, and flow rate). Membranes employed in UF of milk are usually hydrophilic, which minimizes attraction between membrane surface and present proteins. Therefore, creation of a fouling layer is initiated by soluble salts, mainly $\mathrm{Ca}$ and phosphates (Hausmann et al., 2013). Salt deposition may be accelerated at a lower $\mathrm{pH}$ due to greater salt solubilization from the CN micelle. Patel and Reuter (1985) have also attributed flux impairment during UF processing at lowered $\mathrm{pH}$ to increased concentration of soluble Ca. Upon layer creation, these salts start interacting with the CN micelles, in which the modified structure allows for greater attraction and consequently greater deposition and fouling. However, although the fouling layer appeared thicker at low $\mathrm{pH}$, the rate of flux decline among all runs was similar, which may be indicative of a highly porous layer (Hausmann et al., 2013). Additionally, the low $\mathrm{pH}$ is always accompanied by an
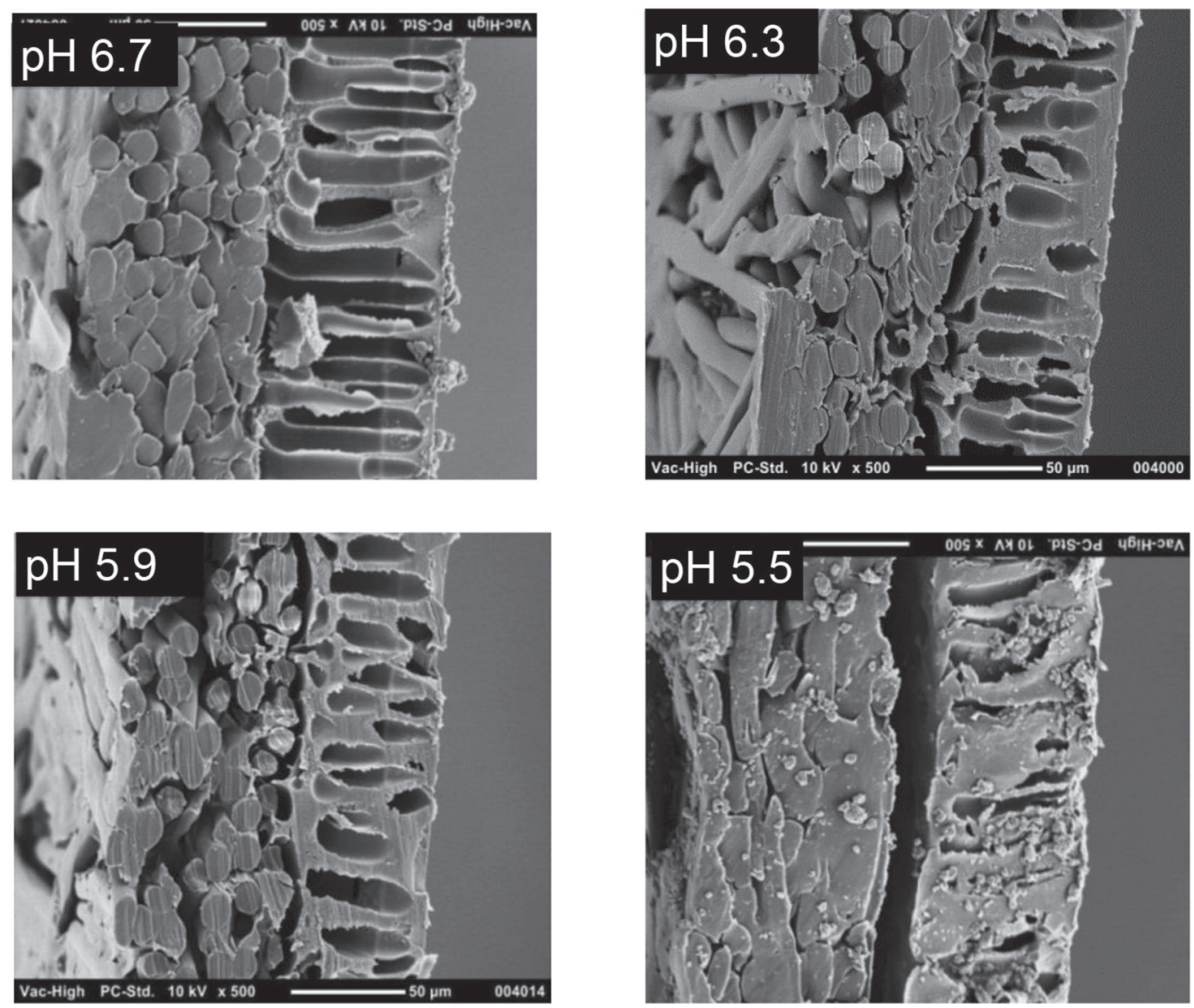

Figure 7. Scanning electron microscopy cross sections of membranes at the end of UF of skim milk with adjusted $\mathrm{pH}$ at $6.7,6.3,5.9$, or 5.5 at $15^{\circ} \mathrm{C}$ and a volume concentration factor of 5 . 
increase in the viscosity of milk, which may further hinder the flux. Viscosity of skim milk can increase by 2.6 times for a VCF between 2 and 5 (Dinkov et al., 2008), which further explains the reduction in flux observed in all samples. All these factors have been implicated in fouling of membranes and questionable process feasibility (Muir and Sweetsur, 1984).

\section{CONCLUSIONS}

The $\mathrm{pH}$ of the skim milk feed had a significant effect on UF operation and the functionality of the final MPC powder. Lowering feed $\mathrm{pH}$ from 6.7 to 5.5 substantially reduced the size of $\mathrm{CN}$ micelle and their zeta potential while enhancing emulsion capability and emulsion stability of the MPC. However, it had a negative effect on the flux due to increased fouling. This was mainly attributed to the removal of $\mathrm{Ca}$ from the $\mathrm{CN}$ micelles and consequent reduction in micelle size during feed acidification and as well as during UF processing of the feed with lowered $\mathrm{pH}$. Possible structural modifications of $\mathrm{CN}$ particles due to depletion of $\mathrm{CCP}$ at low $\mathrm{pH}$ and likely reorganization of individual $\mathrm{CN}$ resulted in smaller particles with enhanced emulsifying properties. The solubility and heat stability of MPC declined with lowering of feed $\mathrm{pH}$, however, restoring the $\mathrm{pH}$ of the MPC dispersions to normal ( $\mathrm{pH}$ 6.7) before analysis improved their functionality possibly due to the restoration of their surface properties. The lowering of the $\mathrm{pH}$, however, reduced the membrane performance with increased membrane fouling resulting in longer times to achieve similar concentration levels. Overall, the most optimum $\mathrm{pH}$ was found to be 5.9 for UF at $15^{\circ} \mathrm{C}$ to obtain MPC with improved emulsifying properties without compromising membrane performance.

\section{ACKNOWLEDGMENTS}

The authors gratefully acknowledge the financial support from the College of Health and Biomedicine, Victoria University, Australia. Authors are also grateful to Geraldine Walker and Michael A. Sciberras from Dairy Innovation of Australia Limited for assistance on the emulsion capacity test and providing the facility for emulsion production.

\section{REFERENCES}

Anema, S. G., and H. Klostermeyer. 1997. Heat-induced, pH-dependent dissociation of casein micelles on heating reconstituted skim milk at temperature below $100^{\circ} \mathrm{C}$. J. Agric. Food Chem. 45:11081115.

Becher, P. 2001. Emulsions: Theory and Practice. Oxford University Press, Oxford, UK.
Cameron, D. R., M. E. Weber, E. S. Idziak, R. J. Neufeld, and D. G. Cooper. 1991. Determination of interfacial area in emulsions using turbidimetric and droplet size data: Correction of the formula for emulsifying activity index. J. Agric. Food Chem. 39:655-659.

Carbonaro, M., and A. Nucara. 2010. Secondary structure of food proteins by Fourier transform spectroscopy in the mid-infrared region. Amino Acids 38:679-690.

Dalgleish, D. G. 2006. Food emulsions-Their structures and structure-forming properties. Food Hydrocoll. 20:415-422.

Dalgleish, D. G., and A. J. R. Law. 1988. pH-Induced dissociation of bovine casein micelles. I. Analysis of liberated caseins. J. Dairy Res. 55:529-538.

Dalgleish, D. G., and A. J. R. Law. 1989. pH-Induced dissociation of bovine casein micelles. II. Mineral solubilization and its relation to casein release. J. Dairy Res. 56:727-735.

Dickinson, E. 1992. An Introduction to Food Colloids. Oxford University Press, Oxford, UK.

Dickinson, E. 1997. Properties of emulsions stabilized with milk proteins: Overview of some recent developments. J. Dairy Sci. 80:2607-2619.

Dickinson, E., and M. Golding. 1997. Depletion flocculation of emulsions containing unadsorbed sodium caseinate. Food Hydrocoll. 11:13-18.

Dinkov, K., M. Dushkova, and N. Toshkov. 2008. Regression models for density and viscosity of ultrafiltration milk concentrates. Bulg. J. Agric. Sci. 14:542-548.

Dissanayake, M., S. Liyanaarachchi, and T. Vasiljevic. 2012. Functional properties of whey proteins microparticulated at low $\mathrm{pH}$. J. Dairy Sci. 95:1667-1679.

Eissa, A. S., C. Puhl, J. F. Kadla, and S. A. Khan. 2006. Enzymatic cross-linking of $\beta$-lactoglobulin: Conformational properties using FTIR spectroscopy. Biomacromolecules 7:1707-1713.

Ezeh, V. N., and M. J. Lewis. 2011. Milk reversibility following reduction and restoration of pH. Int. J. Dairy Technol. 64:179-187.

Ferragut, V., and A. Chiralt. 1996. Microstructure of oil-in-water lowfat emulsions containing skim milk powder and locust bean gum. Food Sci. Technol. (Campinas.) 29:648-653.

Gaiani, C., P. Schuck, J. Scher, J. J. Errhardt, E. Arab-Tehrany, M. Jacquot, and S. Banon. 2009. Native phosphocaseinate powder during storage: Lipids released onto the surface. J. Food Eng. 94:130-134.

Gaucheron, F. 2005. The minerals of milk. Reprod. Nutr. Dev. 45:473483.

Ghatak, P. K., A. K. Bandyopadyay, and M. P. Gupta. 1989. The relation between the heat stability of milk and its chemical composition. J. Dairy Res. 8:165-168.

Griffin, M. C. A., R. L. J. Lyster, and J. C. Price. 1988. The disaggregation of calcium-depleted casein micelles. Eur. J. Biochem. 174:339-343.

Halling, P. J. 1981. Protein stabilized foams and emulsions. Crit. Rev. Food Sci. Nutr. 15:155-203.

Haque, E., B. R. Bhandari, M. J. Gidley, H. C. Deeth, S. M. Møller, and A. K. Whittaker. 2010. Protein conformational modifications and kinetics of water-protein interactions in milk protein concentrate powder upon aging: Effect on solubility. J. Agric. Food Chem. 58:7748-7755.

Hausmann, A., P. Sanciolo, T. Vasiljevic, M. Weeks, K. Schroën, S. Gray, and M. Duke. 2013. Fouling of dairy components on hydrophobic polytetrafluoroethylene (PTFE) membranes for membrane distillation. J. Membr. Sci. 442:149-159.

Havea, P. 2006. Protein interactions in milk protein concentrate powders. Int. Dairy J. 16:415-422.

Holt, C. 1992. Structure and stability of bovine casein micelles. Adv. Protein Chem. 43:63-151.

Holt, C. 1995. Effect of heating and cooling on the milk salts and their interaction with casein. Pages 105-133 in Heat Induced Changes in Milk. P. F. Fox, ed. IDF special issue 9501, International Dairy Federation, Brussels, Belgium.

Holt, C., D. T. Davies, and A. J. R. Law. 1986. Effect of colloidal calcium phosphate content and free calcium ion concentration in 
milk serum on the dissociation of bovine casein micelles. J. Dairy Res. 53:557-572.

Kaliappan, S., and J. A. Lucey. 2011. Influence of mixtures of calciumchelating salt on the physicochemical properties of casein micelles. J. Dairy Sci. 94:4255-4263.

Kher, A., P. Udabage, I. McKinnon, D. McNaughton, and M. A. Augustin. 2007. FTIR investigation of spray-dried milk protein concentrate powders. Vib. Spectrosc. 44:375-381.

Kong, J., and S. Yu. 2007. Fourier transform infrared spectroscopic analysis of protein secondary structures. Acta Biochim. Biophys. Sin. (Shanghai) 39:549-559.

Law, A. J. R., and J. J. Leaver. 1998. Effects of acidification and storage of milk on dissociation of bovine casein micelles. J. Agric. Food Chem. 46:5008-5016.

Lefevre, T., and M. Subirade. 2001. Molecular structure and interaction of biopolymers as viewed by Fourier transform infrared spectroscopy: Model studies on $\beta$-lactoglobulin. Food Hydrocoll. 15:365-376.

Lewis, M. J. 2011. The measurement and significance of ionic calcium in milk. A review. Int. J. Dairy Technol. 64:1-13.

Li, Y., and M. Corredig. 2014. Calcium release from milk concentrated by ultrafiltration and diafiltration. J. Dairy Sci. 97:5294-5302.

Liu, Y., and R. Guo. 2008. pH-Dependent structures and properties of 690 casein micelles. Biophys. Chem. 136:67-73.

Liyanaarachchi, W. S., L. Ramchandran, and T. Vasiljevic. 2015. Controlling heat induced aggregation of whey proteins by casein inclusion in concentrated protein dispersions. Int. Dairy J. 44:21-30.

Lucey, J. A., C. Gorry, B. O'Kennedy, M. Kalab, R. Tan-Kinita, and P. F. Fox. 1996. Effect of acidification and neutralization of milk on some physico-chemical properties of casein micelles. Int. Dairy J. 6:257-272.

Luo, X., L. Ramchandran, and T. Vasiljevic. 2015. Lower ultrafiltration temperature improves membrane performance and emulsifying properties of milk protein concentrates. Dairy Sci. Technol. 95:15-31.

Matia-Merino, L., and H. Singh. 2007. Acid-induced gelation of milk protein concentrates with added pectin: Effect of casein micelle dissociation. Food Hydrocoll. 21:765-775.

McKenna, A. B. 2000. Effect of processing and storage on the reconstitution properties of whole milk and ultrafiltered skim milk powders. PhD thesis. Massey University, Palmerston North, New Zealand.

McMahon, D. J., and B. S. Oommen. 2013. Casein micelle structure, functions, and interactions. Pages 185-211 in Advanced Dairy Chemistry: Proteins. 4th ed. P. F. Fox and P. L. H. McSweeney, ed. Springer, New York, NY.

Mellema, M., P. W. N. de Groot, and M. Golding. 2009. Impaired or accelerated aggregation of proteins in sterilised milk by adding surfactants. Int. Dairy J. 19:728-736.

Morr, C. V., B. German, J. E. Kinsella, J. M. Regenstein, J. P. Van Buren, A. Kilara, B. A. Lewis, and M. E. Mangino. 1985. A collaborative study to develop a standarized food protein solubility procedure. J. Food Sci. 50:1715-1718.

Muir, D. D., and A. W. M. Sweetsur. 1984. Optimization of the heat stability of protein-rich concentrates prepared by ultrafiltration of skim-milk. J. Food Technol. 19:263-271.

Nair, P. K., D. G. Dalgleish, and M. Corredig. 2013. Colloidal properties of concentrated heated milk. Soft Matter 9:3815-3824.

O'Connell, J. E., and P. F. Fox. 2003. Heat induced coagulation of milk. Pages 887-930 in Advanced Dairy Chemistry. P. F. Fox and P. L. H. McSweeney, ed. Kluwer Academic/Plenum Publishers, New York, NY.

Patel, R. S., and H. Reuter. 1985. Fouling of hollow fibre membranes during ultrafiltration of skim milk. Milchwissenschaft 40:731-733.
Pearce, K. N., and J. E. Kinsella. 1978. Emulsifying properties of proteins. Evaluation of a turbidimetric technique. J. Agric. Food Chem. 26:716-723.

Pierre, A., and G. Brule. 1981. Mineral and protein equillibria between the colloidal and soluble phase of milk at low temperature. J. Dairy Res. 48:417-428.

Pouliot, Y., and M. Boulet. 1995. Observations on the seaonal variations in the salt balance of concentrated milk. Int. Dairy J. 5:75-85.

Rabiller-Baudry, M., H. Bouzid, B. Chaufer, L. Paugam, D. Delaunay, O. Mekmene, S. Ahmad, and F. Gaucheron. 2009. On the origin of flux dependence in $\mathrm{pH}$-modified skim milk filtration. Dairy Sci. Technol. 89:363-385.

Remondetto, G. E., and M. Subirade. 2003. Molecular mechanisms of $\mathrm{Fe}^{2+}$-induced $\beta$-lactoglobulin cold gelation. Biopolymers 69:461469.

Schuck, P., and B. Demeler. 1999. Direct sedimentation analysis of interference optical data in analytical ultracentrifugation. Biophys. J. 76:2288-2296.

Schuck, P., M. A. Perugini, N. R. Gonzales, G. J. Howlett, and D. Schubert. 2002. Size-distribution analysis of proteins by analytical ultracentrifugation: Strategies and application to model systems. Biophys. J. 82:1096-1111.

Silva, N. N., M. Piot, A. F. de Carvalho, F. Violleau, A.-L. Fameau, and F. Gaucheron. 2013. pH-induced demineralization of casein micelles modifies their physico-chemical and foaming properties. Food Hydrocoll. 32:322-330.

Srilaorkul, S., L. Ozimek, B. Ooraikul, D. Hadziyev, and F. Wolfe. 1991. Effect of ultrafiltration of skim milk on casein micelle size distrbution in retentate. J. Dairy Sci. 74:50-57.

St-Gelais, D., S. Hache, and M. Gros-Louis. 1992. Combined effect of temperature, acidification and diafiltration on composition of skim milk retentate and permeate. J. Dairy Sci. 75:1167-1172.

Sweetsur, A. W. M., and D. D. Muir. 1980. The use of permitted additives and heat-treatment to optimize the heat-stability of skim milk and concentrated skim milk. J. Soc. Dairy Technol. 33:10-11.

Udabage, P., I. R. McKinnon, and M. A. Augustin. 2000. Mineral and casein equilibrium in milk: Effects of added salts and calciumchelating agents. J. Dairy Res. 67:361-370.

Udabage, P., A. Puvanenthiran, J. A. Yoo, C. Versteeg, and M. A. Augustin. 2012. Modified water solubility of milk protein concentrate powders through the application of static high pressure treatment. J. Dairy Res. 79:76-83.

Van Hooydonk, A. C. M., H. G. Hagedoorn, and I. J. Boerrigter. 1986 $\mathrm{pH}$-induced physico-chemical changes of casein micelles in milk and their effect on renneting. 1. Effects of acidification on physicochemical properties. Neth. Milk Dairy J. 40:281-296.

Vasbinder, A. J., and C. G. de Kruif. 2003. Casein-whey protein interactions in heated milk: The influence of $\mathrm{pH}$. Int. Dairy J. 13:669-677.

Vasiljevic, T., and P. Jelen. 1999. Temperature effect on behavior of minerals during ultrafiltration of skim milk and acid whey. Milchwissenschaft 54:243-246.

Vreeman, H. J., B. W. Van Markwijk, and P. Both. 1989. The structure of casein micelles between $\mathrm{pH} 5-5$ and 67 as determined by light-scattering, electron microscopy and voluminosity experiments. J. Dairy Res. 56:463-470.

Walstra, P. 1990. On the stability of casein micelles. J. Dairy Sci. 73:1965-1979.

Williams, R. P. W., L. D'ath, and B. Zisu. 2008. Role of protein aggregation in heat-induced heat stability during milk powder manufacture. Dairy Sci. Technol. 88:121-147.

Ye, A. 2011. Functional properties of milk protein concentrates: Emulsifying properties, adsorption and stability of emulsions. Int. Dairy J. $21: 14-20$. 